\title{
7. Institutionalized costs and international migration patterns
}

\section{Saibal Kar*}

\section{INTRODUCTION}

Analyzing cross-border labor migration has been one of the most complex yet interesting subjects for research in labor economics, international economics, and public economics, among others. It also delves into the political economy and strongly influences public policy in different countries. Furthermore, the need to understand the scope and dynamics of labor migration with diverse impacts on source and host countries spans various disciplines and school of thoughts. This chapter focuses on investigating the influence of source country policies on emigration patterns. A dedicated public policy is expected to facilitate collection of tax revenues and use them further to compensate for any unwarranted impact of labor migration - such as "brain drain." There appears to be a deterministic pattern of migration from source countries when migrants face institutional costs such as exit taxes (payable at the time of leaving a country). The reference to exit taxes is by no means a policy designed to curb emigration from source countries. Instead, they can be used to improve the stock of human capital in source countries - with established welfare implications (Stark and Wang, 2002) - and could eventually promote more skilled than unskilled emigration from developing countries. In particular, they could be used to create incentives for relatively unskilled workers to learn new skills and then consider emigration. To understand the scope of this policy, this chapter surveys studies covering the established relationship between trade, public policies, and labor mobility. Those focused more on the observed complementarity between trade and migration are discussed.

One of the reasons for this emphasis is that labor migration increasingly emanates from developing economies, which individually and collectively have also seen international trade rise substantially with more advanced host economies during the period studied. Indeed, the relationship between trade and migration is not only borne out by statistical analysis, but also suggests distinctive patterns of migration across countries. 
Section 2 reviews related studies; Section 3 discusses the policy background; Section 4 develops a model with migration tax and applies numerical solutions, while Section 5 concludes.

\section{THE LITERATURE}

Hypotheses on the relationship between migration patterns and possible determinants have been widely studied. For example, several argue that the presence of asymmetric information between source and host countries is an important criterion influencing migration patterns. Another line of argument posits that the availability of public goods in advanced economies often acts as a magnet attracting migrants. It is also well known that - apart from pull factors - economic and/or political instability in source countries can often push workers to migrate (a detailed survey and modeling of these and related issues are available in Acharyya and Kar, 2014; Beladi and Kar, 2015). These and several other lines of discussion define the scope of this chapter.

Many studies show that international trade and labor migration are complements rather than substitutes, at least in the short run (see Schiff, 1994; Marjit and Beladi, 2002; Schiff, 1996; Narayan and Smyth, 2006; Kugler and Rapoport, 2011, among others). In general, this implies that trade liberalization will temporarily lead to more migration-not lessand create a short-run migration hump. Existing studies offer at least three plausible explanations for this positive relationship. First, by creating new employment in source countries, trade liberalization provides families with a means to finance international migration, which they could not afford otherwise. Second, as factor usage can shift in affected sectors following trade reforms, there would be some economic costs involved in transferring resources from one sector to another. This can cause transitional unemployment and therefore encourage more workers to emigrate. And, third, if the most protected import-competing sectors in the economy are labor intensive, then trade liberalization could boost unemployment, generating a push factor for worker migration (mainly unskilled) or create an incentive to boost training.

\subsection{Migration among ASEAN Members}

The short-run complementarity between trade and migration following trade reform will increase migration above the usual quasi-concave trend line. Conversely, over the long run, substitutability between trade and migration will cause the hump to slide downward. It is crucial to note 
that most of these studies provide fairly scant information on how the migration pattern differs across skill types. For example, expansion of trade within the Association of Southeast Asian Nations (ASEAN) could also lead to greater skilled labor mobility. It is important to enquire if other factors - such as institutional costs associated with migration - offer complementary explanations.

Even when opportunities for migration are available, associated costs can often be restrictive and alter perspectives of expected relationships. Therefore, quantifying the cost range for these relationships could be useful for policymakers either for or against greater worker mobility in many countries. In fact, knowing these institutional costs can better measure the exact amount of wage premium needed before skilled and unskilled workers decide against migrating. Notably, migration costs can take many forms and operate through an individual worker's preferences. For example, Faini and Venturini (1993a, b) discuss how rising incomes make the cost of leaving one's own country onerous, as seen for migrants moving from south to north Italy or within Portugal. The specific cost examined in this chapter is a tax paid by migrants differing by skill type. It is important to mention that the few studies that investigate this possibility do not agree on whether these policies are socially desirable or which skill type should be preferred. Indeed, for many policymakers the issue of migration taxes on skill types remains moot. They are both sensitive topics within ASEAN. Yet, their relevance for ASEAN migration is noteworthy - the Philippines previously used these policies.

Also, it is important to remember that education is often not a good predictor of skill development or attainment-using the skilled versus unskilled categorization of workers has its inherent problems. Nevertheless, this chapter offers some observations on migration patterns of skilled versus unskilled labor for a select number of ASEAN countries. These show that in recent years skilled workers tend to migrate more than unskilled workers. Across skill types, pull and push factors may substantially differ and may be influenced by several country-specific factors. For example, using British Panel Data, Rabe and Taylor (2012) show that workers decide to migrate based on pull factors - such as expected wage, employment opportunities, and housing prices prevalent at the destination. Individual characteristics observed (with unobserved heterogeneity corrected) at the source matter very little. Fafchamps and Shilpi (2013) use the Nepal Living Standard survey to show that migrants prefer less variation in terms of ethnic background of groups at host destinations; prefer high-density areas with more public amenities; and feel comfortable in places where many speak their language. Compared with these, several studies show that lack of opportunities, or political and/or 
religious persecution, influences emigration much more than host-country characteristics. All of these represent different forms of costs. The continuing Syria-Europe migration (asylum seekers/refugees) is an example of the push factors causing migration. ${ }^{1}$

It seems that the choice of migration by skill type and how it responds to changes in trade patterns may alter significantly when accounting for skill distribution. It might also require additional explanations beyond the trade-migration link. There is some apprehension (Gois, 2015) that migration into or within the ten-member ASEAN region sometimes qualifies as "irregular" migration-mostly women domestic workers (or in other sectors) not included as those typically engaged in manufacturing and services. This may have to do with distribution of skills across migrant cohorts. ASEAN members largely acknowledged this by adopting the Agreement on the Promotion and Protection of the Rights of Workers (2012), through an initiative of the Law Reform Commission of Thailand. The Agreement harbors a broader vision in that it should be applicable to all workers - recognizing the equal status of migrant workers, particularly those engaged in caregiving and domestic work. Negotiations focused on building consensus among ASEAN members in each article of the draft. The Agreement was finalized in October 2015. Recent developments thus allow a deeper look into the causes behind observed migration patterns beyond that predicted by international trade. Also important to policymakers is whether observed migration trends are welfare enhancing for host and/or source countries. On the one hand, if more skilled migrants join the workforce of a given country, productivity and output should improve. On the other hand, as there may be complementarity within migrant groups by skill type, relatively unskilled migrants may follow skilled migrants, with very different implications for the labor market and for development trajectories.

\section{THE POLICY BACKGROUND OF MIGRATION TAXES}

The existence of pure asymmetric information in cross-border labor markets implies that employers in the migrant country cannot discern the true skill type and productivity of immigrant job seekers, at least initially. This could lead to wage pooling across skill types. ${ }^{2}$ Pooling is the weighted average of respective payoffs across skill types. Pooling equilibrium can result from cultural and physical distances between source and origin countries because information is not readily interpretable and information systems between the two (or multiple) countries differ significantly. It may 
also happen when workers are relatively young, without experience, and lack credentials to prove their productive capacity at time of entry.

Large "north-south" migrations beyond past colonial and later Commonwealth connections usually suffer from this information distortion. But the problem is quite generic and could also apply to rural-urban migration, where skill levels are not interpreted uniformly. The information asymmetry may also occur across sectors located in more than one country, given differences in work culture, nature of entrepreneurship practiced across locations, and adaptability of potential migrants. The last of these often translates into a discount factor (as in Katz and Stark, 1987). According to this specification, the more distant cultural and traditional practices are - considerable differences in food habits or the high cost of living away from family and friends, for example - the more they accumulate into a discount factor. The larger the inverse of the discount factor, the lower the post-migration income compared with pre-migration returns. The rate of discount should be much lower for migration between less heterogeneous countries. However, some asymmetric information-related costs can be reduced by "signals" from prospective immigrants - information or readily verifiable credentials sent out at a cost. These signal costs could nonetheless be restrictive for certain sections of the population. Alternatively, foreign employers use screening devices (mechanisms to isolate the more productive from the less productive) to sort workers prior to offering jobs. At the same time, there is no uniform screening device globally that can help measure the productivity of immigrant job seekers on the spot.

Currently, despite the availability and transmission of huge amounts of information via electronic media, asymmetric information continues to be a dominant feature of the host country's migrant labor market. ${ }^{3}$ Thus, in many cases employers prefer to administer a spot-market-pooled wage for both skilled and unskilled workers. In this regard, Katz and Stark (1987) showed that across a continuum of skills, the pooled wage offer in the host country may fail to attract high-skilled workers. In that case, signaling by high-skilled workers directly could be the only feasible tool to restore information symmetry and guarantee appropriate labor market returns by skill type.

We argue that despite asymmetric information and the initial disadvantage faced by skilled workers, the wage premium generally has been sufficient to create brain drain from developing countries. Decades of research have engaged with corrective mechanisms and some of these find their way back into concurrent debates. The urge to relocate in the Republic of Korea; Hong Kong, China; or Singapore for ASEAN migrants is directly attributed to this income incentives leading to brain drain. Indeed, flows would be much greater when information symmetry returns over time, via 
networks, reputation, and language proficiency, among others. There may however, be specific selection processes for migrants to more advanced economies. Point-based immigration systems - adopted in Australia, for example - directly favor more skilled workers. In this chapter the example of exit taxes is used as a form of cost - given their renewed importance and relevance in less-developed economies' policies (Bradford, 2013 and Desai et al., 2009, 2004 discuss this clearly and in considerable depth).

The reason for invoking exit taxes here is two-fold. First, the skillspecific exit taxes are based on citizenship rather than residence. This follows, for example, the United States (US), Philippines, and Eritrea model. There were two economic and legal issues that motivated Jagdish Bhagwati's initial recommendation for using exit taxes (see Bhagwati, 1987, p. 53). These include no representation without taxation and a brain drain reversal. Depending on the complexity of cross-country agreements and administrative costs, it can also be considered an income tax on foreign-earned income - an additional cost for prospective emigrants. The Philippines raised \$23 million between 1973 and 1976 using a 1-3\% flat tax. Presently, US citizens on average repatriate $\$ 100$ billion in foreignearned income annually.

Second, the revenue implications of skill-specific taxes are calculated when migration is sensitive to tax rates. This can help determine whether the fiscal implications of exit taxes are at odds with evolving migration patterns. Instead of exit tax rates, migration-related remittances and deposits could also be taxed, as in the Philippines: $50 \%$ of overseas foreign workers' (OFWs) foreign currency deposits held jointly with a spouse or any other family member are liable to a $7.5 \%$ tax. In many countries, including India (the largest recipient of migrant remittances), nonresident foreign currency deposits are tax exempt if the worker is away from the country for at least 189 days. The Philippines' top host destinations for OFWs include Saudi Arabia; the United Arab Emirates; Hong Kong, China; Qatar; Singapore; and Kuwait, among others. In these destinations migration is encouraged to the extent it delivers back a portion of what would be lost in revenues otherwise. Naturally, if high-skilled migrants remit to home, revenues could be much greater even with lower tax rates. Eritrea, however, is restricted by the United Nations (UN) from collecting migrant taxes as a sanction against the current regime. Yet Eritrean embassies reportedly continue to collect a $2 \%$ diaspora tax in many countries. The policy is clearly engrained in the US since 2008, when Internal Revenue Code (IRC) $877 \mathrm{~A}$ expatriation rules were enacted such that:

(i) the average annual net income tax for the 5 years ending before the date of expatriation or termination of residency is more than a specified amount 
adjusted for inflation $(\$ 151,000$ for $2012, \$ 155,000$ for $2013, \$ 157,000$ for 2014 , and $\$ 160,000$ for 2015);

(ii) the nonresident's net worth is $\$ 2$ million or more on the date of expatriation or termination of residency; or

(iii) the nonresident fails to certify on Form 8854 that he/she have complied with all US federal tax obligations for the 5 years preceding the date of expatriation or termination of residency.

To summarize, exit taxes were first recommended by Bhagwati and Partington (1976) and faced several legal, political, and economic controversies. In fact, there are many arguments for and against migrant taxes. Briefly, Bhagwati $(1979,1987)$ proposed using migrant tax revenue for development spending and to address the politically sensitive issue of representation without taxation. Similarly, Straubhaar and Wolburg (1998) discussed the legitimacy of taxing skilled emigration. A few countries also numerically evaluated taxing schemes. For example, an exit tax for H1-B workers ${ }^{4}$ from India to the US alone (Desai et al., 2004) at the rate of $\$ 10,000$ per H1-B worker can generate $\$ 500$ million, with revenues supporting education (skill development) at various levels. ${ }^{5}$ Importantly, the revenue implications of emigration by various skill levels are not discussed in this literature. The model here intends to capture this possibility.

\section{MODEL AND RESULTS}

Let there be a continuum of skilled workers denoted by $S \in[0, \bar{S}]$ originating in a developing country $(P)$. They earn $w_{P}(S)$ at the source and, if they migrate successfully to a developed country $(R)$, they earn wage $w_{R}(S)$ if their skill level is interpreted with symmetric information: $w_{R}(S)>$ $w_{P}(S) \forall S$. As worker productivity is not known with symmetry, risk-averse employers offer pooled wage $\bar{W}(S)$ to all workers migrating from the developing to the developed country, at least until the true productivity of the worker is revealed. The measure of this pooled wage is given by

$$
\bar{W}(S)=\frac{\int_{0}^{S} w_{R}(S) F(S) d s}{\int_{0}^{\bar{S}} F(S) d s}
$$

Presently $S$ is defined over one type of occupation only - say, engineers (but could be extended to include other types) - and the distribution 
captures variation in their skill level. Also, $\bar{S}$ is assumed to be the top skill level migrating and $F(S)$ is the probability density function of the distribution of skill. However, each worker receives an average of the entire group because individual skill levels are not known with certainty. Suppose the average wage in (7.1) corresponds exactly with a skill level $S^{*}$. Therefore, $S>S^{*}, \forall S \in\left[S^{*}, \bar{S}\right]$ workers shall not migrate, while $S \leq S^{*}, \forall S \in\left[0, S^{*}\right]$ workers would certainly consider migrating, but this would truncate the highest skill level migrating under asymmetric information to $S^{*}<\bar{S}$.

This could get more complicated. Consider a skill-invariant discount factor applied on post-migration wage, $0<k<1$. Then, a worker computes $\left[k W_{R}(S)-\mathrm{W}_{P}(S)\right]$ to decide whether to migrate or not. The worker migrates if $k W_{R}(S)>\mathrm{W}_{P}(S)$. The gap is non-decreasing in $S .^{6}$ Importantly, there may be multiple values of $S$ for which $\left[k W_{R}(S)-\mathrm{W}_{P}(S)=0\right]$. However, if information were symmetric to begin with, then the true wage of those who did not migrate under asymmetric information would be higher, or $\left.k W_{R}\left(S^{*}\right) \geq k \bar{W}_{R}\left(S^{*}\right)\right]$ if $S^{*}$ is the top migrating group. Consequently, all $S \geq S^{*}$ should always migrate under symmetric information when $S^{*}$ was the top migrating group under asymmetric information. One can see that the migration pattern changes considerably by allowing more skilled workers to migrate when the regime of asymmetric information across countries switches to symmetric information.

Suppose that informational symmetry is reinstated through signaling by individual workers at a fixed $\operatorname{cost} C$. This could take the form of training with country-specific relevance, qualifying in a global competitive examination, or acquiring advanced language abilities, among others. Earlier, it was shown that the opportunity to signal allows more skilled workers to migrate (see Katz and Stark, 1987). More specifically, it was claimed that if skill type $S^{*}$ invests in the device and migrates, then all $S>S^{*}$ should ideally do the same. The signal helps bypass the wage-related disadvantage faced by skilled workers distributed in a continuum of skill levels. A numerical example presently argues that including migrant income taxes on actual earnings at the host country complicates - or even reverses - the migration pattern. This first requires choosing an appropriate tax rate based on the objective function of the tax authority. Here, one can safely assume the government intends to maximize tax revenues. ${ }^{7}$

So, in addition, consider that a tax rate $t_{S}$ is imposed on skill type $S$ on a prospective migrant's foreign-earned income $W_{R}(S)$. Note that the provision of signaling allows skill type $S$ to treat $W_{R}(S)$ as the relevant wage instead of $\bar{W}(S)$ when deciding whether to migrate or not. Therefore, using the above conditions, a skill type $S$ migrates, iff,

$$
k W_{R}(S)-C-t_{S} W_{R}(S) \geq W_{P}(S)
$$


Table 7.1 Skill groups and wages

\begin{tabular}{lrrr}
\hline & \multicolumn{3}{c}{ Skill Group } \\
\hline Wages & I & II & III \\
$W_{P}(\$)$ & 1 & 3 & 10 \\
$W_{R}(\$)$ & 2 & 6 & 20 \\
Proportion in population & $3 / 10$ & $3 / 10$ & $4 / 10$ \\
\hline
\end{tabular}

Source: Katz and Stark (1987).

A skill type $S$ will migrate if the tax rate is

$$
t_{S}^{*} \leq\left[k-\frac{W_{P}(S)+C}{W_{R}(S)}\right]
$$

To verify the applicability of these tax schemes, recall Table 1 from Katz and Stark (1987). There are three distinct (discrete) skill types that would consider migrating for work-I, II, and III (Table 7.1). The hourly wage for types I, II, and III at home are $\$ 1, \$ 3$, and $\$ 10$, respectively. The same in the foreign country are $\$ 2, \$ 6$, and $\$ 20$, respectively. The proportion of type I skill in the workforce is 0.3 , that of type II is 0.3 , and for group III it is 0.4. Migration of skill level from $P$ matches the distribution $F(S)$ in $R$.

Using Equation (7.1), under pure asymmetric information the average wage payable to all workersin $R$ is $\bar{W}(S)=\$ 10.4[=2 * 0.3+6 * 0.3+20 * 0.4$ ], when the top skill type migrating is III. With a discount factor, $k=0.6$, it is immediately seen that group III earns $0.6 \times 10.4=\$ 6.24<W_{P}(I I I)=\$ 10$ and does not migrate under pure asymmetric information. If group III does not migrate, then the highest level migrating is group II. The average wage at the destination becomes $\bar{W}(\mathrm{~S})=\$ 4$, as the workforce now consists of two types of skill level only. Their individual productivities are not known by employers in $R$. After discount, the hourly wage of type II falls below $\$ 3$ and dissuades them from migrating. It turns out that only group I migrates, as it earns $0.6 \times \$ 2=\$ 1.2<W_{P}=\$ 1$.

Now consider signaling by prospective migrants. Let the fixed cost of signaling be $C=\$ 1.8$, once the workers signal they expect to receive the true wage in $R$ instead of the pooled wage. Therefore, skill type I will not signal because these workers cannot get less than $\$ 2$, which, after discounting with $k=0.6$, allows them to migrate. Group II would not invest in signaling since $W_{R}(I I)=0.6 \mathrm{X} \$ 6-\$ 1.8=\$ 1.8<W_{P}(I I)=\$ 3$. These workers will not migrate unless they have a rather small measure for $k$. Finally, group III invests in signaling as they earn $0.6 \times \$ 20-\$ 1.8=\$ 10.2>W_{P}=\$ 10$. Thus, signaling allows skill types I and III to migrate, while type II stays home. 
This is different from pure asymmetric information, when only group I migrated. This part of the model is already available in previous studies. The reason for reporting it is the possibility that a migration tax could change this pattern. The possible outcomes including a migration tax have not been discussed previously, or looked at by policymakers. In terms of the tax rates to be imposed, it is easy to see that using a progressive migration tax rate may lead back to the case under pure asymmetric information.

So, using Equation (7.2) and Table 7.1, group I shall continue to migrate, if $t_{I}^{*} \leq 0.1$ and group III shall continue to migrate, if, $t_{I I}^{*} \leq 0.01$. $t_{I}^{*}$ is calculated in the following way: holding $k=0.6$, from Equation (7.3) $t_{I}^{*} \leq\left[0.6-\frac{1+0}{2}\right]=0.1$, as $C_{I}=0$ (because type I does not signal), $W_{P}(I)=1$, and $W_{R}(I)=2$. This would be the same if asymmetric information existed because, as shown above, only type I workers migrate under no information. Overall, type I does not migrate if the tax rate imposed on them exceeds $10 \%$, while group III does not migrate if the tax rate imposed on them exceeds $1 \%$.

Finally, the onus lies in finding the precise conditions that can sustain this type of tax scheme. The migration tax should be regressive (meaning the tax rate falls as income rises) so long as the government upholds the principle of revenue maximization. Consider the objective function of the government as

$$
\begin{aligned}
& \operatorname{Max} T=\int_{0}^{S} t_{S}^{*} W_{R}(S) F(S) d s \\
& \text { subject to: } t_{S}^{*} \leq \bar{t}_{S}
\end{aligned}
$$

where $\bar{t}_{S}$ is the maximum rate that can be imposed for a particular type at which the individuals are indifferent as to whether to migrate or not. This added specification in (7.4) now offers a modified set of conditions displayed in Table 7.2. Note that, if type I and III both migrate, then the tax rate needs to be different as calculated above, or both brought down to the lower of the two rates if it has to be uniform (no difference in tax rates across skill types). So, the policymaker can choose from a feasible set of tax rates such as: (i) a uniform tax rate; (ii) a progressive tax rate (the tax rate rises as income rises); or (iii) a regressive tax rate. However, the revenue implications of each are markedly different. This can be seen below, where the choice of tax rates both dictates the migration pattern and generates revenue.

Case 1: Using the specifications in Table 7.1, suppose a uniform tax rate is imposed. The total tax revenue accruing to the government (Equation 7.3) when type I and III migrate is given by 
$T=X_{I} t_{I}^{*} W_{R}(I)+X_{I I I} t_{I I}^{*} W_{R}(I I I)=0.3 \times 0.01 \times 2+0.4 \times 0.01 \times 20$ $=\$ 0.086$ where, $X_{S}=$ proportion in population, $S \in[I, I I, I I I] ; t_{I}^{*}=t_{I I I}^{*}$ $=0.01(1 \%)$

Case 2: If the tax rate is progressive and yet allows migration of both types I and III, then the maximum tax rate across all groups would be one that makes type III indifferent as to whether to migrate or not, or $t_{I I I}^{*}=0.01(1 \%)$ according to the example in Equation (7.5). Naturally, the tax imposed on type I has to be lower. Evidently, the revenue generated cannot be more than that in case 1 .

Case 3: If a uniform tax is imposed on both types I and III, but the rate is the same as that imposed on type I in Equation (7.5), then type III refrains from migrating. The tax revenue is lower than in cases 1 and 2 and is the same as that collected under pure asymmetric information.

Case 4: Finally, as already discussed, if the tax rates are regressive, the revenue is maximized.

These cases are estimated numerically in Table 7.2.

Overall, if potential migrants use a signaling device to reinstate informational symmetry (such that skill types I and III both migrate), then the tax authority earns maximum revenue from imposing migrant taxes if and only if the tax scheme is regressive $\left(\frac{d t *}{d S}<0\right)$. In other words, based on the earlier discussion about the principle of exit taxes in Section 3, the numerical results show that a lower tax rate imposed on higher-skilled workers could maximize revenue collection at the time of exit. Similarly, if exits and

Table 7.2 Tax rates, migration decisions, and tax revenues

\begin{tabular}{|c|c|c|c|c|c|}
\hline \multirow{2}{*}{$\begin{array}{l}\text { Information } \\
\text { Regime }\end{array}$} & \multicolumn{2}{|c|}{ Tax Rate } & \multicolumn{2}{|c|}{ Skill Type } & \multirow{2}{*}{$\begin{array}{l}\text { Total Tax Revenue } \\
\text { (Tax type) }\end{array}$} \\
\hline & $t_{I}$ & $t_{I I I}$ & I & III & \\
\hline Pure Asymmetry & $10 \% *$ & NA & Migration & No Migration & $\$ 0.060$ \\
\hline \multirow[t]{4}{*}{ Signaling } & $1 \%$ & $1 \% *$ & Migration & Migration & $\begin{array}{l}\text { \$0.086 (Low } \\
\text { Uniform) }\end{array}$ \\
\hline & $0.5 \%$ & $1 \% *$ & Migration & Migration & $\$ 0.083$ (Progressive) \\
\hline & $10 \% *$ & $10 \%$ & Migration & No Migration & $\begin{array}{l}\$ 0.060 \text { (High } \\
\text { Uniform) }\end{array}$ \\
\hline & $10 \% *$ & $1 \% *$ & Migration & Migration & $\begin{array}{l}\$ 0.140 \\
\text { (Regressive)*** }\end{array}$ \\
\hline
\end{tabular}

Note: * Maximum tax rate for $S$; *** Maximum Tax Revenue.

Source: Author's calculations. 
inward remittances are both taxed, then a regressive structure could again be better at generating revenues for the source country.

Instead, suppose that revenue maximization is not the sole objective of the government, and it additionally uses policy to completely restrict skilled workers' emigration from the country. The tax scheme may then be progressive, such that group I is taxed at $10 \%$ but group III is taxed above $10 \%$ (with revenue earned only \$0.06). Consequently, type III would not find migration profitable. This is a situation where the top skill group migrating under asymmetric information, but with signaling, is not higher than that under pure asymmetric information. Conversely, unskilled migration may be completely restricted by imposing a strongly regressive tax rate $(\geq 10 \%$ for group I and 1\% for III). The results provide consequences for income distribution in the source country. This deserves future attention.

\section{CONCLUSIONS}

This chapter merges two previously disjointed angles of study. One is about migration patterns under asymmetric information; the other is about migration taxes as a viable policy instrument for supporting development expenditures in less developed countries. This tax policy is used to investigate the plausible patterns of migration across skill types when asymmetric information exists between source and host countries. An example is provided that shows evolving migration patterns could differ from those generally observed when migration taxes and asymmetric information regarding the true productivity level of immigrant labor exist.

The results obtained here show that policymakers can use migration taxes as an instrument to influence both the stock and flow of migrant workers in a country. The large outflow of skilled workers from less developed countries and their concentration in a few chosen locations attract capital and could create considerable disparities in regional economic outcomes. In the contemporary world of technology-driven production, demand for skilled workers has increased substantially. However, disparities in infrastructure do not allow skilled workers to take advantage of these improvements in most locations. Skill's mobility through migration is often a response to this inability of the source country to retain its best talent. Obviously, the "brain drain" of skilled workers implies a loss on several fronts, but may also have some positive impact on remaining workers. The peer effect of skilled workers migrating to a more prosperous location and earning a higher income positively influences subsequent generations to acquire appropriate skills. While that might more than compensate for any loss in current output, a country could use many other policies that better 
control outcomes. One of these might be a migration tax as discussed in this chapter. The choice of tax not only influences the pattern of migration but is also expected to influence future choices. In particular, the proposed regressive migration tax offers incentives to the relatively unskilled to acquire skills before attempting to migrate. As a final caveat, we need to appreciate that the possibility explored here is just one of many competing procedures that could be adopted to influence migration patterns and facilitate skill acquisition at the same time.

\section{NOTES}

* The author thanks the Asian Development Bank, and in particular Elisabetta Gentile, for facilitating this research.

1. See also Docquier and Rapoport (2012) and Beine et al. (2008) for elegant surveys.

2. See Beladi and Kar (2015), Friedberg (2000), Chau and Stark (1999), Katz and Stark $(1989,1987)$, Kwok and Leland (1982), among others.

3. Borjas (2000) shows that foreign-born teaching assistants (and their communication skills) are often less preferred to native teaching assistants by United States (US) undergraduates. It is well known that US universities make substantial use of a well-developed screening mechanism when offering admission and financial aid to such foreigners. Cultural distance (at least on arrival), despite high merit among the foreign-born teaching assistants, remains a disquieting factor for such jobs.

4. The H-1B is a visa in the United States under the Immigration and Nationality Act, section 101(a)(15)(H) that allows U.S. employers to temporarily employ foreign workers in specialty occupations. A specialty occupation requires the application of specialized knowledge and a bachelor's degree or the equivalent of work experience. The duration of stay is three years, extendable to six years; after which the visa holder may need to reapply. Laws limit the number of H-1B visas that are issued each year: 180,440 new and initial H1-B visas were issued in 2017. Employers must generally withhold Social Security and Medicare taxes from the wages paid to employees in H-1B status. https://www.uscis.gov, Department of Homeland Security, Government of United States (retrieved, March 18, 2019).

5. Migration taxes are just one of many migration control measures tried either by source or host countries. For example, Thum (2004) modeled rich country governments to choose the level of public goods provision preferred by immigrants. These are determined by the median voter's income at home. Lower provision is considered a discriminatory tax on immigrants, and thus dissuades immigration.

6. The value of $k$ may be decreasing in $S$ because the top skill groups in $P$ often follow similar lifestyles as their counterparts in $R$. This could lead to a non-monotonic migration pattern.

7. If the tax is collected in $R$ under some tax-sharing agreement between $R$ and $P$ (as per the initial proposal), then it further supports the cause for revenue maximization, because of the high administrative costs involved.

\section{REFERENCES}

Acharyya, R. and S. Kar (2014), International Trade and Economic Development, Oxford: Oxford University Press. 
Beine, M., F. Docquier and F. Rapoport (2008), 'Brain Drain and Human Capital Formation in Developing Countries: Winners and Losers', Economic Journal, 118, 528, 631-52.

Beladi, H. and S. Kar(2015), 'Skilled and Unskilled Immigrants and Entrepreneurship in a Developed Country', Review of Development Economics, 19, 3, 666-82.

Bhagwati, J. (1979), 'International Migration of the Highly Skilled: Economics, Ethics and Taxes', Third World Quarterly, 1, 3, 17-30. Reprinted in Robert Feenstra (ed.) (1987), International Economic Theory, Vol. 2, Cambridge, MA: MIT Press.

Bhagwati, J. (1987), International Economic Theory, Vol. 2., ed. Robert Feenstra, Cambridge, MA: MIT Press.

Bhagwati, J. and M. Partington (1976), Taxing the Brain Drain: A Proposal, Amsterdam: North-Holland.

Borjas, G. (2000), 'The Case for Choosing More Skilled Immigrants', American Enterprise 11, 8, 30-31.

Bradford, A. (2013), 'Sharing the Risks and Rewards of Economic Migration', University of Chicago Law Review, 80, 1, 29-58.

Chau, N.H. and O. Stark (1999), 'Migration under Asymmetric Information and Human Capital Formation', Review of International Economics, 7, 455-83.

Desai, M., D. Kapur and J. McHale (2004), 'Sharing the Spoils: Taxing International Human Capital Flows', International Tax and Public Finance 11: 663-93.

Desai, M., D. Kapur, J. McHale and K. Rogers (2009), 'The Fiscal Impact of High Skilled Emigration: Flows of Indians to the U.S.', Journal of Development Economics, 88, 1, 32-44.

Docquier, F. and H. Rapoport (2012), 'Globalization, Brain Drain, and Development', Journal of Economic Literature, 50, 3, 681-730.

Fafchamps, M. and F. Shilpi (2013), 'Determinants of the Choice of Migration Destination', Oxford Bulletin of Economics and Statistics, 75, 3, 388-409.

Faini, R. and A. Venturini (1993a), 'Italian Migrations: The Pre-war Period', in T. Hatton and J. Williamson (eds), International Migration and World Development, 1850-1939, London: Routledge.

Faini, R. and A. Venturini (1993b), 'Trade, Aid and Migration: Some Basic Policy Issues', European Economic Review, 37: 435-42.

Friedberg, R. (2000), 'You Can't Take It with You? Immigrant Assimilation and the Portability of Human Capital', Journal of Labor Economics, 18, 2, 221-51.

Gois, A. W. (2015), 'Labour Migration in the ASEAN Region', Heinrich Böll Stiftung: The Green Political Foundation.

Katz, E. and O. Stark (1987), 'International Migration under Asymmetric Information', Economic Journal, 97, 387, 718-26.

Katz, E. and O. Stark (1989), 'International Labour Migration under Alternative Informational Regimes: A diagrammatic Analysis', European Economic Review, 33, 127-42.

Kugler, M. and H. Rapoport (2011), 'Migration, FDI and the Margins of Trade', CID Working Paper No. 222, Harvard University.

Kwok, V. and H. Leland (1982), 'An Economic Model of the Brain Drain', American Economic Review, 72, 91-100.

Marjit, S. and H. Beladi (2002), 'The Stolper-Samuelson Theorem in a Wage Differential Framework', Japanese Economic Review, 53, 2, 177-81.

Narayan, P.K. and R. Smyth (2006), 'What Determines Migration Flows from Low-Income to High-Income Countries? An Empirical Investigation of FijiU.S. Migration 1972-2001', Contemporary Economic Policy, 24, 2, 332-42. 
Rabe, B. and M.P. Taylor (2012), 'Differences in Opportunities? Wage, Employment and House-Price Effects on Migration', Oxford Bulletin of Economics and Statistics, 74, 6, 831-55.

Schiff, M. (1994), How Trade, Aid, and Remittances Affect International Migration, Washington, DC: World Bank.

Schiff, M. (1996), South-North Migration and Trade: A Survey, Washington, DC: World Bank.

Stark, O. and Y. Wang (2002), 'Inducing Human Capital Formation: Migration as a Substitute for Subsidies', Journal of Public Economics, 86, 1, 29-46.

Straubhaar, T. and M. Wolburg (1998), 'Brain Drain and Brain Gain in Europe: An Evaluation of the East-European Migration to Germany', in Managing Migration in the 21st Century, Winter 1998 Workshop, Center for US-Mexican Studies, University of California, San Diego.

Thum, M. (2004), 'Controlling Migration in an Open Labor Market', Public Choice, 119, 3-4, 425-43. 